\title{
Agent-Based Modelling of Values: The Case of Value Sensitive Design for Refugee Logistics
}

\author{
Christine Boshuijzen-van Burken', Ross Gore ${ }^{2}$, Frank Dignum ${ }^{3}$, \\ Lamber Royakkers ${ }^{4}$, Phillip Wozny ${ }^{5}$, F. LeRon Shults ${ }^{6}$
}

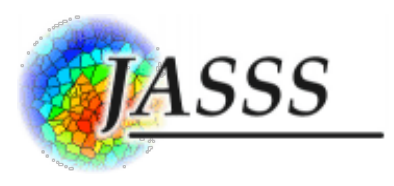

${ }^{1}$ School of Engineering and Information Technology, University of New South Wales, Canberra 2600, Australia

${ }^{2}$ Virginia Modeling Analysis and Simulation Center, Old Dominion University, 1030 University Blvd., Suffolk VA 23435, United States

${ }^{3}$ Department of Computing Science, Umeå Universitet, 90187 Umeå, Sweden

${ }^{4}$ Faculty of Industrial Engineering \& Innovation Sciences, Eindhoven University of Technology, PO Box 513, 5600 MB, Eindhoven, The Netherlands

${ }^{5}$ Deloitte Tax \& Legal, Gustav Mahlerlaan 2970, 1081 LA, Amsterdam, The Netherlands

${ }^{6}$ Department of Global Development and Social Planning, University of Agder, Universitetsveien 19, Kristiansand Vest-Agder 4604, Norway

*Correspondence should be addressed to christinevanburken@gmail.com

Journal of Artificial Societies and Social Simulation 23(4) 6, (2020). Doi: 10.18564/jasss.4411 Url: http://jasss.soc.surrey.ac.uk/23/4/6.html

Received: 01-04-2019 Accepted: 10-08-2020 Published: 31-10-2020

\begin{abstract}
We have used value sensitive design as a method to develop an agent-based model of values in humanitarian logistics for refugees. Schwartz's theory of universal values is implemented in the model in such a way that agents can make value trade-offs, which are operationalized into a measure of refugee wellbeing and a measure of public opinion about how the refugee logistics is being handled. By trying out different 'valuescenarios', stakeholders who are responsible for, or involved in refugee logistics can have insights into the effects of various value choices. The model is visualized and made usable as a platform (interactive website) for decision-makers to understand the trade-offs in policies for government and non-government organizations.
\end{abstract}

Keywords: Agent Based Model, Value Sensitive Design, Simulation and Policy, Humanitarian Logistics, Refugees, Schwartz Values

\section{Introduction}

1.1 Agent based modelling can be a helpful method for simulating social systems, by modelling behavioural interactions between distinct agents. In this article, we describe a case of using agent-based modelling to show the joint effects of decisions of key stakeholders that are responsible for humanitarian refugee logistics in the Netherlands, on refugee wellbeing. In line with the value sensitive design methodology (Friedman \& Hendry 2019), we give explicit attention to values in the logistics processes around refugees. We use Schwartz's theory of basic human values, because it is an established system of values that lends itself for the purpose of modelling. In this article, the concept of humanitarian logistics is understood broadly, and includes both the procedural steps in the asylum procedure and the organization of concrete logistical matters such as housing, transport and daily activities through which an asylum seeker goes until he or she has obtained refugee status. The reason why we leave the procedural part and the concrete tangible part of refugee logistics together in our research, is that in reality they are highly intertwined: the procedural step in which an asylum seeker finds herself defines what she can or cannot do (volunteering, studying, working, travelling, etc.) and what her housing situation looks like before reaching the legal refugee status. This research is not about emergency housing of UNHR worldwide, but offers an examination of how values that are reflected in the procedures and processes do have a direct effect on the practical logistics and refugee wellbeing in refugee hosting countries Vluchtelingenwerk 2019a). The perception of how the Netherlands deals with the refugee situation is somewhat polarized where one group of people feels more should be done to satisfy the needs of refugees, while another group feels that the Netherlands prioritizes the needs of refugees over the needs of Dutch citizens. ${ }^{1}$ It is therefore essential 
that the logistical process concerning refugees goes well. But what exactly does this mean, a 'good' refugee logistics? We approach the problem through an ethically oriented analysis of refugee logistics, constructing an agent-based computer model with which we can simulate the refugee chain. The 'agents' in the computer model represent various stakeholders and organizations that offer support in the refugee process. The chosen approach does justice to the different perspectives and values of each stakeholder. Simulations can then be done with the model, serving as a communication tool between the parties, so that together, using the model, various stakeholders can explore how certain (policy) choices create potential conflicts between values of other stakeholders in the refugee chain. Ideally, this can lead to solutions for good cooperation between the parties and therefore to a better refugee logistics process.

1.2 In order to turn the rather technical part of the agent-based model into a usable asset for policy makers, we have developed an interactive user-friendly website that can be used as a discursive tool for stakeholders that are involved in important value-based decisions concerning refugee logistics. In this way, the stakeholders can show one another how the actions jointly have a better or worse effect on refugee wellbeing, as well as on public opinion about how the refugee logistics is being handled. This latter part is important for policy makers, who need to remain sensitive to societal responses to policy implementation.

1.3 It is important to note that the term 'refugee' formally denotes a legal status. However, in the remainder of this article it is loosely used to refer to those people who are either externally displaced (who have not (yet) registered in the hosting country) or are in the process of requesting asylum. We also use the more neutral term 'newcomer' for them, as this is now the preferred term for most NGOs in the Netherlands. ${ }^{2}$

1.4 In this article, we discuss the principal result, which is a value sensitive agent-based model of humanitarian logistics for refugees in the Netherlands, whereby different scenarios are examined through simulations of the model. With our model and simulation, we aim to support decision makers (e.g., policymakers, NGOs, legal authorities) dealing with a rather urgent practical situation, namely, the situation of refugees in the Netherlands, through providing a discursive tool which supports them in voicing impacts of their own actions and actions of others on the overall outcome of refugee logistics. Our team of researchers has developed a model and an interactive website based on the model that has been tested and presented to several stakeholders involved in refugee logistics in the Netherlands. The website visualizes a measure of wellbeing for refugees and a measure of Dutch residents' public-opinion about how the management of refugees is handled (to be clear: not public opinion about refugees in general). We start with some background information and a brief working definition of humanitarian logistics in the Netherlands, followed by a discussion of the methods we use. Then we discuss the agent-based model and the computer simulation. We conclude with a critical discussion of the model in terms of philosophical concerns as well as empirical issues that have been raised in stakeholder meetings where we presented and tested the model.

\section{Background}

2.1 As of 30 June 2018, UNHCR reported a total population of people on the run from war and violence of 70.4 million people (UNHCR 2019). During the first half of 2018, at least 5.2 million people were newly displaced and fewer people could return to their home countries, due to ongoing hostilities in e.g. Syria and increasing problems in South America. The globally displaced population included 20.2 million refugees under UNHCR's mandate ${ }^{3}$ and 3.2 million asylum-seekers ${ }^{4}$. According to international conventions asylum seekers are those people that are fleeing their home country due to war or violence and that request protection in another country. After a successful asylum application, refugee status is obtained and the refugee can live in the hosting country, often for the duration of several years initially. The Netherlands, like many other countries, hosts refugees under the 1951 Convention. The total number of asylum applications in the Netherlands increased to almost 58,880 in 2015, of which 27,710 come from Syria (Vluchtelingenwerk 2019b). In 2018 the number had dropped to 30.380 requests (ibid). Especially during the period of high influx of asylum seekers, the Netherlands has experienced various challenges in the field of humanitarian logistics for refugees. It appeared to be a difficult task to organize and execute the refugee chain ${ }^{5}$ in a logistically good manner. The biggest challenges in the logistics process are related to good coordination between parties that serve asylum seekers such as the Immigration and Naturalization Service (IND), the Central Agency for the Housing of Asylum Seekers (COA) and various social or voluntary organizations, such as Vluchtelingenwerk Nederland (VWN). Although many organizations do their utmost to keep the logistics process in order, there are cases in which a refugee remains stuck in the refugee migration and asylum process for a prolonged period, sometimes due to lack of coordination and cooperation between major stakeholders. In the Netherlands people stayed in the pre-processing locations, 
with limited facilities, for months (http://www.asylumineurope.org/news/12-09-2018/netherlands-processingtimes-increase-length-asylum-procedures) (AIDA 2018 |2019). Another risk for good logistics for refugees is that hosting countries lose societal goodwill for supporting refugees (Oltermann 2016).

\section{Related Research}

3.1 Izquierdo et al. (2008) discuss a general method for understanding equilibrium states for social dilemmas, through reinforced learning dynamics with agent-based models. This approach resembles our exploration of value trade-offs in refugee policies, as well as participatory modelling (Voinov \& Bousquet|2010), as it implicitly includes the values of stakeholders in the modelling process. Furthermore, our agent-based model builds on the work of Silverman \& Bharathy 2005) which explores modelling personality and cognition at the agent level. Mercuur et al. 2019) modelled a psychological experiment on dividing money in which the agents had values and norms, which has similarities with our model. Our model differs from previously mentioned models, because we implement values in a manner consistent with the established Schwartz's theory of values (Wozny 2018).

3.2 In the field of refugees research several agent-based models have been developed to model bottom-up dynamics related to refugees. For example, Suleimenova \& Groen (2020) developed an agent-based model to predict the effect of policy decisions in the South Sudan conflict on camp arrival rates of displaced persons. They included camp border closure, camp capacity change and forced redirection and the distribution of refugees over camps in neighbouring countries. Collins and Frydenlund built an agent-based model which models group formation during long distance movement (2016). The model is a theoretical exploration that characterizes the process of flight from conflict as a payoff variable which slows down movement but increases security. Groen (2016) developed an agent-based model that simulates flight from violent conflict through a strictly movementoriented lens. Similarly, Hebért et al. (2018) and Suleimenova et al. (2017) used different geo-spatially explicit agent-based models to predict flight destinations following violent conflict. Unlike the previously mentioned movement models, which focused on movement within a single or small cluster of states, Hattle et al. (2016) applied a similar methodology to migration into Europe. Crooks \& Hailegiorgis 2014) and Hailegiorgis \& Crooks (2012) have developed a number of agent-based models of the spread of cholera within and between refugee camps. Anderson et al. (2007) have developed a health focused agent-based model that includes both refugees and the institutions responsible for their care. The model includes a weighted set of desires in a manner similar to the inclusion of values in our model.

3.3 Keeney (1996), Gregory \& Keeney (1994) and (Keeney \& von Winterfeldt 2007) developed deliberative value focused decision analytic models that were put to use in several different contexts, for example ecological decision making (Zia et al.|2011), airport systems (Curran et al.|2011) and, somewhat related to our research, for improving cargo delivery planning in disaster aftermath (Brandaõ Cavalcanti et al.2017).

\section{Methods}

4.1 This research combines methods from the social sciences and computer science. In this section the different methods are systematically addressed.

\section{Value sensitive design}

4.2 The overall methodological framework stems from value sensitive design (Friedman et al. 2006), which is a tri-partite design methodology consisting of conceptual, empirical and technical investigations. The conceptual part consisted mainly in using Schwartz theory of basic universal human values (1992:2012) to implement values in the model. The empirical part consists of stakeholder interviews and group meetings. The technical design or product consists of building an agent-based model and interactive website. The website was delivered to the stakeholders and tested in a feedback session. An important step in our research was to make the most important values in the refugee chain explicit. The Participatory Design approach van der Velden \& Mörtberg 2014 was used for generating the most important values from the stakeholders through interviews and stakeholder meetings, including a Group Decision Room (Gray 2008, Kolfschoten et al. 2011), which is a computer-based anonymous group discussion method. Fourteen refugees who had been through the asylum process and who were granted asylum in the Netherlands were interviewed ${ }^{6}$. Most of them had fled from Syria, 
but some came from Ethiopia or Eritrea and most were male. By using Ulrich's Critical Systems Heuristics 2003 approach for stakeholder selection, an overview of the parties in the refugee chain that either caused or mitigated the problems was created. In this way it could be decided which parties, from the perspective of the refugee, deserve a place in the agent-based model. In addition to interviews with refugees, representatives of organizations that work with refugees and that were clearly related to the (problems in the) refugee chain were interviewed and a group decision room was held with them. Amongst these were public servants from the ministry of justice and security, an asylum lawyer, COA and employees of NGOs such as the Salvation Army and Word and Deed (Woord en Daad).

\section{Computer science: Agent-based modelling and social simulations}

4.3 Agent based modelling and social simulations are discussed here only briefly and elaborated upon in the remainder of the paper. Using agent-based modelling is a well-suited approach if the aim is not to offer prescribed solutions, but to simulate the complex context in which the problem resides Axtell 2000 Epstein \& Axtell 1996. We deem the issue of humanitarian logistics for refugees such a case. Value driven behavior is motivated by multiple and often contradictory principles (Schwartz 1992) expressed through policies of governmental agencies and NGOs. In our case the focus is on refugee wellbeing and operational costs of logistics for refugees. The present investigation organizes agent behaviour according to Schwartz theory of values, which is a systematic set of beliefs about the world whose relative importance motivates action (Schwartz \& Bilsky 1990).

4.4 The asylum procedure in the Netherlands provides the logistical structure of the model. It is complemented with values to simulate agent's preferences and responses to value-driven actions. The agents are key actors in the asylum procedure. The agent-based model is based on the Swartz value theory, but representatives that work in the organizations that are in the model (the "agents") are consulted to get an understanding of what kind of actions represent a value-satisfaction for that organization.

\section{The Agent-Based Model}

\section{Asylum procedure}

5.1 The agent-based model starts with the asylum procedure in the Netherlands. The key actors are asylum seekers, COA, IND - Immigration and Naturalization Service), and Non-Governmental Organization (NGOs). Figure 11shows the asylum procedure. The procedure consists of housing asylum seekers as they move through the varying stages of the legal procedure.

5.2 It proceeds as follows: Before obtaining a formal Asylum Seeker (AS) status, a person who applies for refugee status has the legal status Externally Displaced Person (EDP). He or she receives a health examination and registers as an asylum seeker at the Central Reception Location (COL). After two days, the person is sent to a Process Reception Location (POL) facility where their legal status changes to asylum seeker (AS) and they begin the general asylum procedure. After an intake interview in the POL, IND repatriates asylum seekers from designated safe countries under the Dublin Regulation ${ }^{7}$. If the newcomer appeals the decision or IND requires more time to decide, the newcomer is transferred to the Asylum Seeker Center (AZC) for the extended asylum procedure.

5.3 Their accommodation and care is managed by COA, which tightly controls movement in and out of the AZC, and residents must report regularly (Bakker et al.|2016). NGOs support newcomers both during and after the process by providing information, resources and organizing activities (Dutch Council For Refugees 2016). The asylum procedure lasts from four to eight days. If refugee status is granted, an asylum seeker receives a residence permit, Temporary Residence (TR) status, for five years. Then, the refugee is offered social housing nearby the AZC by a Dutch municipality, which are typically in rural zones. With refugee status, one can receive social security benefits, enroll in a university, and work. Refugees are then obligated to undergo an integration course on Dutch language and culture. After passing the exam, they are then qualified to apply to become a permanent Dutch resident (Bakker et al. 2016). A more detailed discussion of the general Dutch asylum procedure is provided in Wozny (2018).

\section{Schwartz's theory of basic human values}

5.4 The theoretical 'system of values' that we use for the model is provided by social psychologist Shalom Schwartz. His research has shown that people all over the world recognize the importance of a set of ten basic value types 


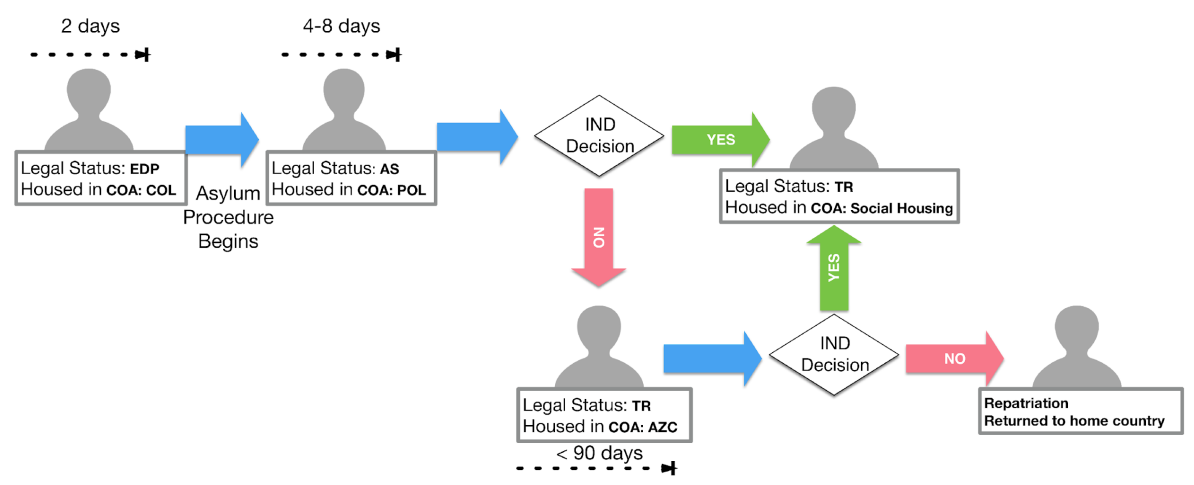

Figure 1: The general Dutch asylum procedure (source: Wozny 2018).

Schwartz 1992, 2006). However, each individual may give each basic value type a different priority. Researchers have also found correlations between what priorities people give to the basic value types. Schwartz therefore calls his list of values universal human values. According to van der Weide (2011), Schwartz's findings are useful in a decision support system because they allow the system to make better predictions concerning an individual's priorities between perspectives, which also allows the system to make better suggestions concerning what values the decision maker cares about in a certain decision context.

5.5 Schwartz's approach to values is pragmatic, in the sense that he considers values to be helpful for three universal requirements of human existence with which values help to cope: needs of individuals as biological organisms, requisites of coordinated social interaction, and survival and welfare needs of groups (1992). People's value priorities depend on what they ought to do to survive and strive for in their social environments. If a person's social environment changes, his or her value priorities may change. For example, Altemeyer \& Smith 1988 found that when people become parents, they tend to find tradition, conformity, and security values more important. Schwartz (1992) proposes a structure between basic values types in which some basic values are congruent and others are often in conflict. Actions in pursuit of tradition values, for example, are often congruent with actions in pursuit of conformity values such as obedience. Other values, such as achievement values often conflict with the pursuit of benevolence values. Figure 2 shows the ten values that Schwartz found. Schwartz deliberately pictured them as a circle, to stress that adjacent value types share some motivational emphases and are compatible, while values that are further away are often more conflicting or even diametrically opposed. This way of organizing values yields four quadrants, or clusters or values, namely Self-Transcendence, Self- Enhancement, Conservation, and Openness-to-Change.

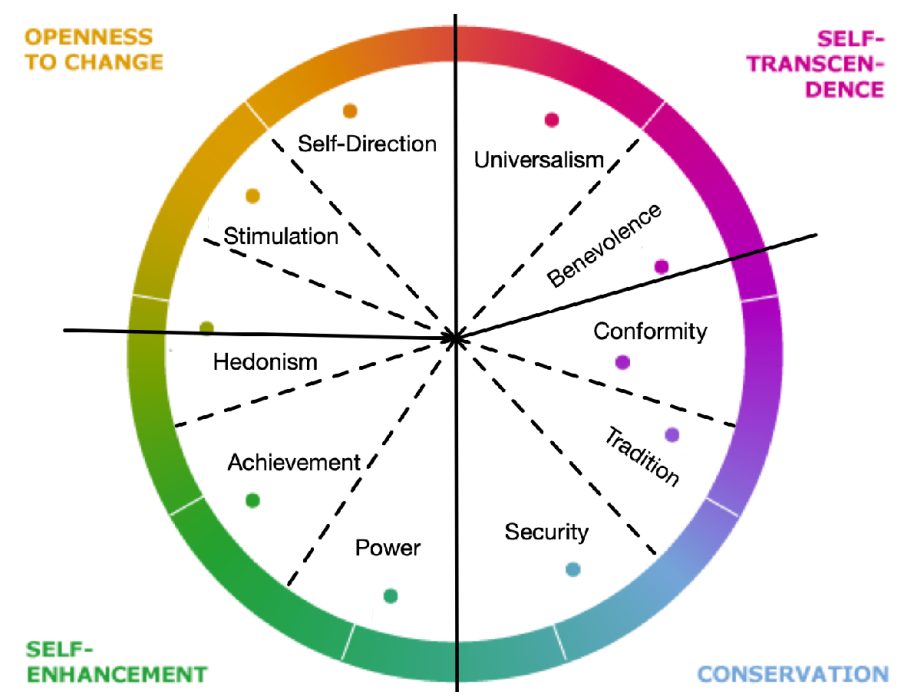

Figure 2: Circle of Schwartz's Theory of Values broken into quadrants (based on Schwartz \& Butenko 2014).

5.6 Some of the values found by Schwartz were also found in our own empirical work. Safety, for example, is mentioned, while privacy is lacking in Schwartz list of values, which could indicate that some values that we found in the group decision room are not as universal as one might think. 


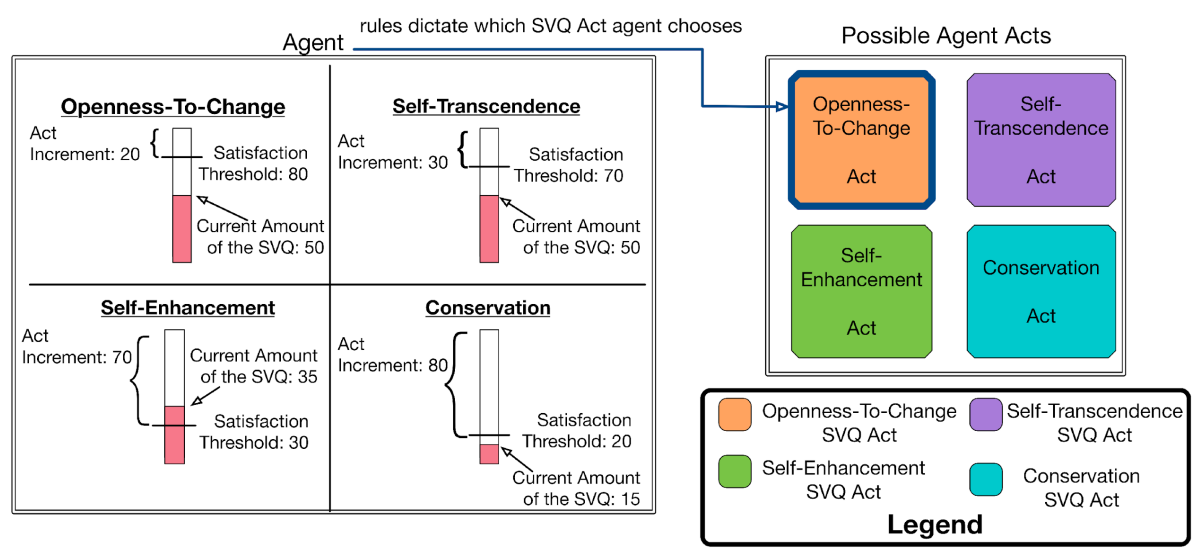

Figure 3: Implementation of Schwartz Value Quadrants (SVQs) within the model.

5.7 Our model explicitly used Schwartz values. For pragmatic (computational/simplicity) reasons we did not use all ten values separately, but rather, we used the four clusters of values, i.e., the value quadrants.

\section{Modelling Schwartz values}

5.8 Here, we explain how the Schwartz Values are implemented in the model, manifested by agents and operationalized into a measure of wellbeing of asylum seekers. An ODD (Overview, Design concepts, and Details) Protocol describing the model is available and can be found in Wozny (2018). The agents in our model 'carry' the four Schwartz Value Quadrants (SVQs), which represent a cluster of Schwartz's Values. The four clusters are: Conservation, Self-Enhancement, Self-Transcendence, and Openness-to-Change. Each Schwartz Value Quadrant (SVQ) is ascribed a satisfaction threshold between $[0,100]$ indicating its importance to the agent. The threshold indicates the relative importance that a particular cluster of values has for the agent: 0 means not important that this cluster of values is satisfied, while 100 means very important that this cluster of values is satisfied. Thus, each SVQ has a threshold, but the threshold differs per individual agent. An example is shown below.

5.9 At any given point in time an agent has a current level of satisfaction of the SVQ which decays uniformly over time. SVQs are satisfied by performing SVQ acts (activities for newcomers, actions for institutional agents), in order words, the decaying SVQ can be 'refilled' (below, on or above the threshold level) by acts or actions. Thus, SVQ acts increment the agent's current amount of a given SVQ. An agent's SVQ is satisfied when the agent's current amount of the SVQ is greater than the agent's satisfaction threshold for the SVQ. The model is built in such a way that each increment amount of an SVQ act is always 100 minus SVQ threshold. This is a design choice in the model, based on the consideration that SVQs with higher satisfaction thresholds require the agent to take more SVQ acts since: (1) the SVQ threshold is high and (2) the high SVQ threshold creates a small SVQ act increment amount. When given an opportunity to choose what act to take an agent chooses the act that once taken will minimize the distance between the amount of the most deficient SVQ and the SVQ threshold. Figure 3 shows an example of this.

5.10 The analogy of a battery could facilitate understanding of the model.

\section{Definitions}

- Red/White Bar - The SVQ, in other words the cluster of values. In the battery analogy this is the battery.

- Line designated 'Current amount of the SVQ' - The amount of value currency that is currently inside the cluster of values. In the battery analogy this is the amount of energy currently inside the battery

- Satisfaction threshold - The minimum amount of value currency that the agent needs to have inside the cluster of values to be a satisfied. In the battery analogy this is the amount of energy that the agent minimally wants to have in the battery to be satisfied with the battery charge.

- Act increment - The amount of value currency that is added to the cluster of values each time an agent performs a valuable action, namely an action that relates positively to the cluster of values. In the battery analogy this reflects each time the battery is given a shot of battery charge. 
5.11 To continue the analogy, the SVQ is a battery which holds energy. The energy is then the value currency which, like any battery, drains at a certain rate (even if no appliance is connected to the battery). An agent can choose which battery it is most important to have a high energy level of. For some batteries $20 \%$ is a satisfactory energy level (e.g., a clock), while for another battery $80 \%$ might be the satisfactory energy level (e.g., for an engine starter). In the same way, an agent can choose which threshold level is satisfactory for which SVQ.

5.12 As with energy in this example of a battery, the amount of value currency also decays over time. In our model, the value currency in an SVQ decays at a constant rate. However, SVQs can be increased, thus potentially satisfied, by performing SVQ acts (activities for newcomers, actions for institutional agents) which increment the agent's amount associated with the SVQ. In terms of the battery analogy: these batteries can be charged so as to increase the amount of energy until they reach, or preferably overshoot, the minimum amount of energy that needs to be in the battery, i.e., the threshold level set by the agent. An agent's SVQ is satisfied when the amount of value currency inside the SVQ is greater than or equal to the satisfaction threshold.

5.13 We have set-up the model in such a way that the increment amount of an SVQ act is 100 - SVQ threshold. The reason for this design choice is that we needed a way to reflect the relative importance of the SVQs with higher satisfaction thresholds. They require the agent to take more SVQ acts, in other words, it is more difficult to satisfy the SVQ that you deem more important. The high SVQ threshold imposes a small increment amount for each act that it deems. When given an opportunity to choose what act to take an agent chooses the act that once taken will minimize the distance between the most deficient SVQ and the SVQ threshold.

\section{Agents}

5.14 Within our model each type of agent has two possible types of acts: (1) obligatory acts and (2) SVQ acts, which are voluntary. Obligatory acts must be completed by the agent when required. Table 1 summarizes the obligatory and optional SVQ acts each agent can take. It is important to note that acts of newcomer agents in our model are activities, and the acts of institutional agents, COA, NGOs and IND are actions. The distinction is made to contrast the fixed set of institutional actions and the changing set of newcomer activities. While both SVQ actions and SVQ activities satisfy SVQs, only newcomer activities have a certain weekly frequency such that the set of possible activities is temporally variable. Please note that the actions or activities are at best (empirically informed) examples of what the agents can do and the list is not exhaustive.

\section{Newcomers}

5.15 Within our model newcomers navigate the general Dutch asylum process shown in Figure 1. During the process, the newcomer is subject to decisions of IND and COA. We explicitly understand the decisions of these agents, as well as to the decisions of newcomers to perform actions, to be value inspired decisions.

5.16 Interview: The first step in the process is the IND Interview, which potentially increases the newcomer's documentation-quality, because the interview report consists of documents to prove their case. The IND, as a government institutional agent, decides on the legal status of the newcomer.

5.17 Activities: Once a newcomer completes their interview, he or she can participate in SVQ activities. Activities made available by either the COA or the NGO include: (1) Custom Activities developed by the NGO, 2) Volunteer (requires NGO to be present), (3) Language Class (requires newcomer to be legal status TR), (4) Football ${ }^{8},(5)$ Work and (6) Study. The values satisfied by these activities are shown in Table 1 The translation between values and activities, in other words, how to interpret a certain activity as a value-satisfier for a specific value, is based on interviews and common-sense reflection on the action or activity at hand. For example, we consider the action 'study' to satisfy the SVQ of "Self-Enhancement", because it increases one's opportunities to be successful in the future. The action "volunteer" (so the newcomervolunteers in the kitchen for example) to satisfy the value "Self-Transcendence".

5.18 Health: Newcomers also have a health attribute that can be satisfied in a more or less adequate manner. The value of health was mentioned in the group decision room. It had initially fallen off the list of most important values, but after discussion it was put back. The value of a newcomer's health ranges between $[0,100]$ and is randomly distributed upon initialization of the model. It represents the physical health of the newcomer and decays at a rate that depends on wellbeing (described next) and the 'health' of the building in which the newcomer resides. Building health reflects a combination of the cleanness of the building and the extent to which the building is maintained. All activities, except for crime, require the newcomer to have a certain level of health for participation in those activities. Newcomers can improve their health by either participating in the 


\begin{tabular}{|c|c|c|c|}
\hline Agent & SVQ/Obligatory & Name & Prerequisite \\
\hline \multirow[t]{9}{*}{ Newcomer } & Obligatory & IND Interview & $\begin{array}{l}\text { Legal Status: EDP \& } \\
\text { Paired with IND con- } \\
\text { ducting } \\
\text { Newcomer }\end{array}$ \\
\hline & Obligatory & Doctor & Health $<30$ \\
\hline & Conservation & Language Class & Legal Status: TR \\
\hline & Self-Enhancement & Work & Legal Status: TR, AS \\
\hline & Self-Enhancement & Study & Legal Status: TR, AS \\
\hline & Self-Enhancement & Crime & $\begin{array}{l}\text { Legal Status: TR, AS \& } 40 \\
<\text { Health }<50 \text { \& Wellbe- } \\
\text { ing }<5\end{array}$ \\
\hline & Openness-To-Change & Football & Legal Status: TR, AS \\
\hline & Self-Transcendence & Volunteer & NGO present \\
\hline & Determined by NGO & Custom Activity & NGO present \\
\hline \multirow[t]{6}{*}{ COA } & Obligatory & Check-in Newcomer & $\begin{array}{l}\text { Paired with Accommo- } \\
\text { dation Change of New- } \\
\text { comer }\end{array}$ \\
\hline & Obligatory & $\begin{array}{l}\text { Construct Accommoda- } \\
\text { tion }\end{array}$ & None \\
\hline & Conservation & Segregate & None \\
\hline & Self-Enhancement & Improve Facilities & None \\
\hline & Openness-To-Change & Adjust Staff & None \\
\hline & Self-Transcendence & Invest & None \\
\hline \multirow[t]{6}{*}{ IND } & Obligatory & Interview Newcomer & $\begin{array}{l}\text { Paired with Newcomer } \\
\text { Participating in IND In- } \\
\text { terview }\end{array}$ \\
\hline & Obligatory & Decide Newcomer & $\begin{array}{l}\text { Paired with Legal Status } \\
\text { Change of Newcomer }\end{array}$ \\
\hline & Conservation & Raise Threshold & None \\
\hline & Self-Enhancement & Issue Statement & None \\
\hline & Openness-To-Change & Lower Threshold & None \\
\hline & Self-Transcendence & Adjust Staff & None \\
\hline \multirow[t]{4}{*}{ NGO } & Conservation & Fundraise & NGO present \\
\hline & Self-Enhancement & Marketing Campaign & NGO present \\
\hline & Openness-To-Change & Custom Activities & NGO present \\
\hline & Self-Transcendence & Prioritize & NGO present \\
\hline
\end{tabular}

Table 1: Agent Obligatory and SVQ acts

Football activity or taking part in the obligatory activity of going to the doctor. The model obligates newcomers to go to the doctor when their health falls below a critically low threshold.

5.19 Wellbeing: We operationalized wellbeing as: 100 minus the average amount that a newcomer's four SVQs are not satisfied. Thus, wellbeing is measured in a $[0,100]$ range where 0 reflects no value satisfaction in any SVQ and 100 reflects complete value satisfaction in all SVQs. Upon initialization newcomers are initialized with SVQ thresholds and SVQ amounts. Both the SVQ thresholds and the SVQ amounts are randomly distributed. An additional activity that is always available to newcomers is Crime. Crime fulfils the Self-Enhancement SVQ. It can occur when: (1) the newcomer is very unsatisfied with respect to the Self-Enhancement SVQ and (2) the newcomer's wellbeing is extremely low (i.e. below 5). Even under these circumstances the newcomer does not necessarily participate in a Crime SVQ activity. A random distribution is sampled to determine if the newcomer will choose to participate. The result is that crime is a rare occurrence that is only manifested by newcomers under specific circumstances. However, when a crime does occur it reduces the city residents' public-opinion of the management of newcomers. The Volunteer activity, on the other hand, which requires an NGO to be present, increases the city residents' public-opinion of the management of newcomers. 
5.20 The IND is the governmental agent responsible for updating the legal-status of a newcomer according to the newcomer's documentation-quality.

5.21 Documentation Quality: The first obligatory action is the interview, which produces an interview report and which may include additional documents to prove the newcomer should be granted asylum. IND's second obligatory action is to: (1) initially decide on a newcomer's asylum case or (2) decide on an appeal to a newcomer's case. IND has distinct thresholds for initial and appeal decisions. When the IND makes a decision, it compares a newcomer's documentation-quality to a threshold such that positive decisions occur if the threshold is exceeded. IND's SVQ actions can influence the parameters of this process. IND can raise the threshold for documentation quality, a Conservation SVQ Action, which increases the effort that is demanded from the newcomer to increase his or her documentation-quality. A high threshold could result in newcomers who possess sufficient documentation of their need for asylum being denied entry into the country. This type of IND decision error is referred to as a false negative as it is a result which incorrectly indicates that sufficient documentation quality for a newcomer is absent. When an IND false negative (FN) decision occurs the city residents' public-opinion of the management of newcomers decreases.

5.22 IND can lower the threshold for documentation quality, which is a Self-Transcendent SVQ Action, which works in exactly the opposite manner. A Lower Threshold decreases the threshold on documentation quality, potentially resulting in IND false positive (FP) decision errors: a result which incorrectly indicates that sufficient documentation quality for a newcomer is present. When an IND FP decision error occurs, the city residents' public-opinion of the management of newcomers decreases too. The importance of documentation quality refers to the second most important value that was mentioned in the group decision room: "Carefulness in the action of the Dutch Government".

5.23 Increase Staff: The remaining IND SVQ actions also relate to the decision process. The IND can choose to increase their staff numbers, which we consider as an Openness-To- Change SVQ action. This provides additional staff at the IND, which means that more cases can be handled in the same amount of time, thus increasing the decision speed, which decreases the number of days a newcomer spends in the COL, POL and AZC facilities waiting to receive a decision from IND.

5.24 Issue Statement: IND can issue a statement in the form of a letter or a press release from the government, potentially dissuading newcomers to come to the country, which we consider an IND Self-Enhancement SVQ action. It reduces the overall number of newcomers in the population.

\section{COA}

5.25 COA is an institutional agent responsible for housing newcomers in the COL, POL, AZC and social housing depending upon where the newcomers are in the general asylum process. The COA also maintains the health of each of these buildings and staffs the buildings with COA employees. Both of the COA obligatory actions are related to managing accommodations of newcomers. The first obligatory action is to Check-in newcomers into their appropriate housing. The second obligatory action is to Construct Accommodation. This reflects COA building additional housing facilities for newcomers when its current housing supply is at capacity.

5.26 Segregate: COA can decide to segregate newcomers, separating those who have yet to receive a final IND decision. This is a Conservation SVQ action. COA sends newcomers with poor document quality to housing locations with worse building health and newcomers with high document quality to housing locations with better building health. Recall that a housing location's building health impacts the health of the newcomers that reside in it.

5.27 Invest: COA can invest by providing travel vouchers to newcomers, which is a Self-Transcendence SVQ action. This allows newcomers to travel to other cities to participate in activities that better meet their SVQ needs.

5.28 Adjust Staff: The COA can adjust staff, which is an Openness-To-Change SVQ action. This increases the staff in housing locations to ensure that newcomers are carefully monitored. More careful monitoring within a COA ensures that when travel vouchers are provided, all newcomers receive one. In addition, careful monitoring ensures that newcomers whose health falls below the critical threshold visit the doctor.

5.29 Improve Facilities: COA can improve facilities, which is a Self-Enhancement SVQ action. This results in repairing and providing maintenance to the COL, POL, AZC and social housing. Repairs and maintenance improve the health of these buildings, which also improves the health of the newcomers residing in them. Improving facilities could potentially lead to increase the value of privacy in the housing facilities (e.g. by making better sound insulations), which is a value mentioned in the group decision room. 
5.30 COA also provides the following activities for newcomers depending on their legal status: (1) Language Classes, (2) Football, (3) Work and (4) Study. These activities are scheduled on specific days of the week and that schedule does not change based on the SVQ needs of the newcomers.

NGO

5.31 NGO is a non-government institutional agent that supports newcomers through the development and scheduling of activities, raising funds from the public, and influencing the public. Unlike the other agents in our model, an NGO agent is not required to be present in cities and does not have any obligatory actions.

5.32 Fundraise: NGOs can fundraise, which is a Conservation SVQ Action. Fundraise is an investment which connects the city residents' public-opinion of the management of newcomers to a willingness for donating funds for the NGO to use in the future.

5.33 Marketing Campaign: The opposite of the Fundraise SVQ action for an NGO is the Self-Enhancement SVQ action, Marketing Campaign. When performing a marketing campaign an NGO uses its funds to influence city residents' public-opinion of the management of newcomers.

5.34 Custom Activities: An NGO can develop Custom Activities, which is a Self-Transcendence SVQ action. When performing a Custom Activities action, an NGO identifies the most unsatisfied SVQ among the newcomers in the city and develops an activity to satisfy it. Initially, the Custom Activity is scheduled for one session on a random day of the week in the model. Every time a Custom Activity is developed the funds of the NGOs decrease. If an NGO does not have sufficient funds, it cannot perform a Custom Activity action.

5.35 Prioritize: An NGO can Prioritize, which is an Openness-To-Change SVQ action, meaning that the NGO adjusts the scheduling of Custom Activities in the city to best meet the current SVQ needs of the population. For example, suppose an NGO has a Custom Activity satisfying the Openness-To-Change SVQ and a Custom Activity satisfying the Conservation SVQ held two days a week. However, the most unsatisfied SVQ of the majority of newcomers in the city is the Conservation SVQ. In this scenario, the NGO Prioritize SVQ action would decrease the number of days the Openness-To-Change Custom Activity is scheduled and increase the number of days the Conservation SVQ is scheduled. Interactions between local Dutch people and newcomers in the setting of NGO activities, such as language buddies and soccer mates, take place on a person-to-person level and can therefore contribute to a feeling of being recognised rather than seen merely as a number in an often overwhelming process and housing location. Thus, activities by NGOs potentially influence the value of receiving respect and honour, or being valued as a human being, which was the fourth most important value mentioned by the group decision room.

\section{Parameters}

5.36 The initial values form the model parameters and are chosen from a uniform distribution shown in Table 2 . A uniform distribution is used to generate a population with equally diverse values. The model allows the user to specify: (1) if NGOs will be present in the cities, (2) if the activities developed by NGOs during the Custom Activity SVQ action will be branded as activities newcomers will participate in and (3) if the activities developed by NGOs during the Custom Activity SVQ action will be developed with an understanding of the most unsatisfied SVQ of the newcomers within the city. This deepening of the model is done to emphasize the importance of cultural sensitivity when organizing activities. For example, the NGO may offer a Custom Activity satisfying OpennessTo-Change in the form of a bicycle riding class. However, even if the activity satisfies an unsatisfied SVQ for a newcomer, he or she may not participate in the class because of native cultural norms where cycling is a children activity, and adults, or women, are not supposed to cycle.

5.37 The model also enables users to specify the initial city residents' public-opinion of the management of newcomers and explore different value parameterizations for the COA, NGO (if present) and IND. An overview of these parameters and the aforementioned parameters are shown in Table 2. Each of the four values (Conservation, Self-Enhancement, Openness-to-Change and Self-Transcendence) are put on a [0-100] scale. In addition, we apply the Schwartz's theory of values constraint that modifications in Conservation alter Openness-to-Change and modifications in Self-Enhancement alter Self-Transcendence. 


\begin{tabular}{ll}
\hline Parameter & Value \\
\hline NGO present in cities & True/False \\
NGO Custom Activities Branded towards Newcomers & True/False \\
(if NGO is present) & \\
NGO Understands Newcomer SVQs for Custom Activ- & True/False \\
ities and Prioritization (if NGO is present) & \\
Initial Public Opinions in Cities (if NGO is present) & {$[0-100]$} \\
COA Conservation & {$[20-80]$} \\
COA Self-Enhancement & {$[20-80]$} \\
COA Openness To Change & $100-$ COA Conservation \\
COA Self-Transcendence & $100-$ COA Self-Enhancement \\
NGO Conservation (if NGO is present) & {$[20-80]$} \\
NGO Self-Enhancement (if NGO is present) & {$[20-80]$} \\
NGO Openness To Change (if NGO is present) & $100-N G O$ Conservation \\
NGO Self-Transcendence (if NGO is present) & $100-N G O$ Self-Enhancement \\
IND Conservation & {$[20-80]$} \\
IND Self-Enhancement & {$[20-80]$} \\
IND Openness To Change & $100-$ IND Conservation \\
IND Self-Transcendence & $100-$ IND Self-Enhancement \\
\hline
\end{tabular}

Table 2: Model Parameters

\section{Model execution}

5.38 With the parameterization as given in Table 2, the model execution occurs through a series of time steps. A uniform distribution is used to generate a population with equally diverse values. Because in general people are different and value different things to different degrees, the SVQs for each newcomer and the satisfaction thresholds are assigned randomly through a uniform distribution. So individual agents were randomly assigned different value thresholds to represent a population with equally diverse values. Satisfaction (SVQ) threshold is also distributed uniformly. The IND, COA or other newcomers do not know the satisfaction threshold of a newcomer and the NGO only knows the most unmet need of all newcomers during a Custom Activity action. This value is important in the model and it is randomly distributed. It does not directly dictate the actions of any other agents, except the NGO during a Custom Activity.

5.39 In each step, newcomers first identify any obligatory acts that are required in the time step. If any of these exist then the newcomer participates in the obligatory act and does not participate in any SVQ activities for the given time step. If no obligatory acts need to be performed, then the newcomer identifies all SVQ activities that can be performed. This depends on the schedule of activities for the day, the health of the newcomer, the legal status of the newcomer, whether the newcomer has been given a travel voucher by COA and whether an NGO is present in their city. Next, COA and IND take any obligatory acts that are required in the time step. It is important to note that this does not preclude COA and IND from taking a SVQ action later in the time step. Then, all agents (newcomers, COA, NGO and IND) identify the available SVQ act which minimizes the distance between the amount of the most deficient SVQ and the SVQ threshold. Thus, each agent performs the action that is most strongly value inspired. Finally, the agent takes the SVQ act and updates its state variables. When an agent performs an SVQ act, the act directly effects other agents within the model.

5.40 A visualization of these direct effects on newcomer wellbeing and city residents' public-opinion of the management of newcomers is shown in Figure 4. Not shown in Figure 4 are indirect effects that can occur within the model with respect to these two outcomes. Direct and indirect effects of acts on other outcomes are also not shown. Model execution terminates after 1,000 time-steps (1 time step equals 1 day). This reflects about three years of time passing where a "steady state" was noticed in the model. Any direct and indirect effects of the model parameters on the agents and the effects of the agent's actions on one another have stabilized.

5.41 1 In order to make the model tangible and visual for practitioners, we made an interactive website, which reproduces the general trends in our agent-based simulation. This website contains various output metrics of samples of simulation runs whose initializations sweep the value parameter space. Figure 5 gives an impression of the website. Notice the drop-down menus in Figure 5 Users of the model can choose different actions for the COA, IND and NGO through the drop-down menus. These actions show underlying value choices and depending on which value is prioritized, the outcome regarding refugee wellbeing and public opinion changes. 


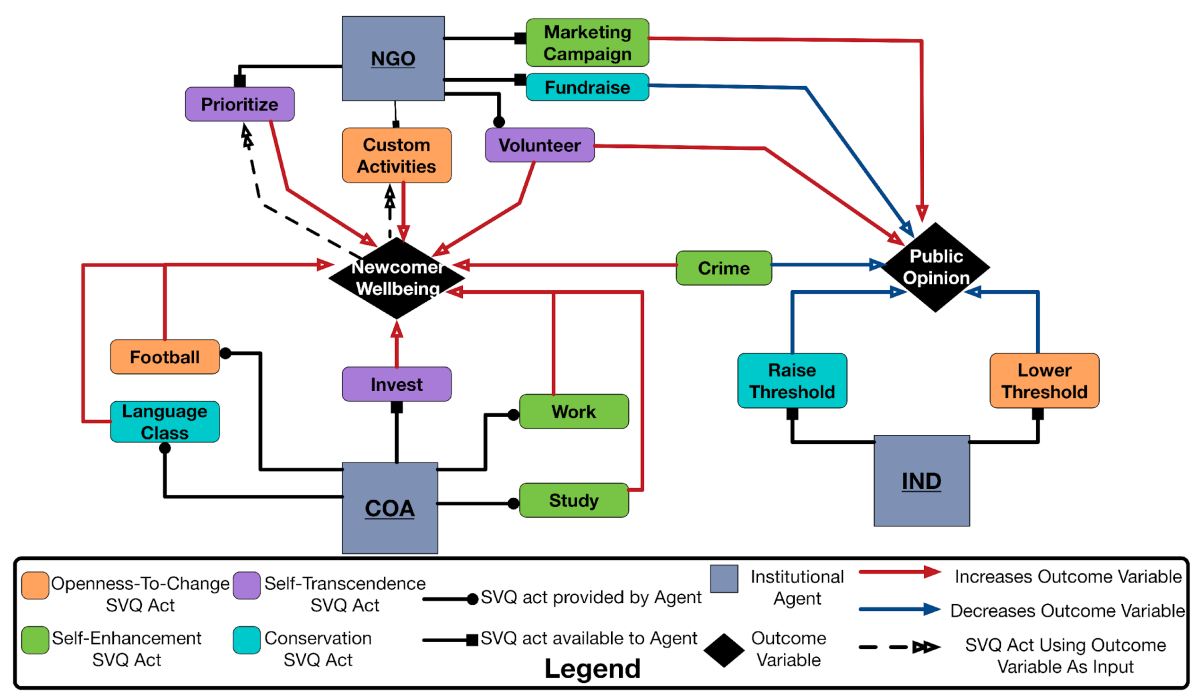

Figure 4: Direct effects on newcomer wellbeing and public opinion of management of newcomers.

The outcome is represented through a red bar (newcomer wellbeing) and a green bar (public opinion of newcomer management) on a $0-100 \%$ scale. 100\% means that newcomers are most satisfied in terms of wellbeing and that city residents are most satisfied with how the management of newcomers is done. We found that for our stakeholders, these two outcomes are important: on the one hand refugee wellbeing is important for the refugees themselves, but also for other stakeholders, such as Vluchtelingenwerk and COA, who then can see the effects of their actions on the refugees, as well as the effects of their actions on the public opinion. Public opinion about the handling of the refugee logistics is important for policy makers, because it serves as feedback from the public that is confronted with how well the Dutch government and other stakeholders handle refugee logistics and eventually this has consequences for the political opinion about the current government.

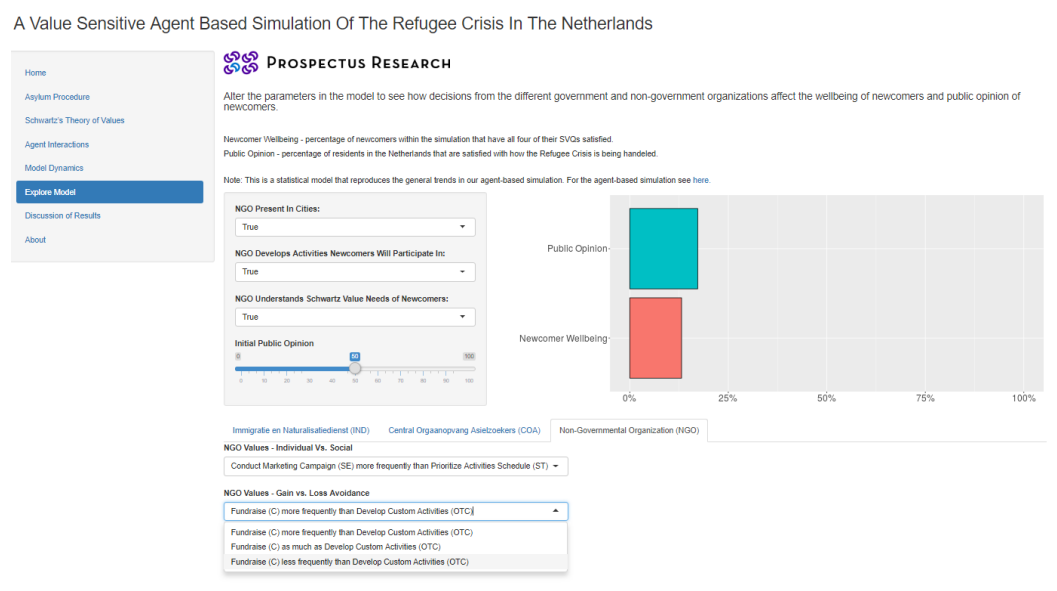

Figure 5: An impression of the interactive website on "value sensitive agent-based simulation of the refugee crisis in The Netherlands". Note: https://rgore-vmasc . shinyapps .io/integration-model/.

\section{Analysis of the model}

5.42 In order to find outcomes that are relevant to the issue at hand, we used a technique called statistical debugging for enhanced trace validation of agent-based models (Gore et al. [2017). Characteristics of agents and the model are tracked over time and then analysed by subject matter experts (SMEs) to gain insight into unexpected and potentially invalid output. Four trace validations were performed on the model. Each of the trace validations were run for 500 time-steps and each time step represents one week. The trace validations highlight how the dynamics of the model optimize and minimize newcomer wellbeing and public opinion. It captures data 
throughout execution (i.e., records a trace of the execution) and uses the data to automatically generate conditions related to the input parameters. In our case, we were interested in conditions that are true about the input parameters when a specified output occurs that is of interest, in particular if refugee wellbeing $=100$, meaning that refugee wellbeing is maximized (see Gore et al. 2019) for a detailed description of the model). The authors, in consultation with SMEs, found the internal dynamics which produced these outcomes valid given the described system.

5.43 While the model allows for creating an array of results depending on the desired insights one wishes to gain, below we present one insight that is derived from the model and that is of potential interest to policymakers, namely the level of newcomer wellbeing.

\section{High level of newcomer wellbeing}

5.44 The model reveals that a high newcomer wellbeing, realized through satisfaction of about $80 \%$ of value needs for all newcomers, is produced through a subtle set of conditions. The presence of an NGO in cities and an understanding of the Custom Activities that newcomers will participate in is required to maximize newcomer wellbeing; these conditions alone are not sufficient. Realizing high newcomer wellbeing also requires: (1) very high initial resident public-opinion of the management of newcomers in the city, (2) an NGO's understanding of unsatisfied newcomer SVQs for Custom Activities and Prioritization and (3) COAs, NGOs and INDs that are higher in Self-Transcendence and Openness-to-Change SVQs than Conservation and Self-Enhancement SVQs. In other words, to maximize newcomer wellbeing, it is important for stakeholders to look beyond their own organizational boundaries.

5.45 The outcomes shown in Figure 6 report on the model execution after 1,000 time steps ( 1 time step $=1$ day). This reflects 3 years of time passing where a "steady state" of the model has been achieved with respect to public opinion and newcomer well-being. The model is parameterized as follows (other than the changes specified in the title of each graph to the IND parameters): NGOs are present in cities, NGO develop activities newcomers will participate in, NGOs understand the Schwartz Value needs of newcomers, and initial public opinion of newcomers is $100 \%$. The COA improve facilities (Self-Enhancement) less frequently than it invests in newcomers (i.e. provides a voucher to newcomers enabling them to travel to other cities to participate in activities) (Self-Transcendence) and the COA segregates newcomers (Conservation) less frequently than it adjusts staffs to meet the needs of newcomers (Openness To Change). The NGOs conduct marketing campaigns (SelfEnhancement) less frequently than they develop Custom Activities (Self-Transcendence) for newcomers and the NGOs fundraise (Conservation) less frequently than they prioritize the scheduling of Custom Activities in the city to best meet the current needs of the newcomers (Openness To Change).

\section{Low level of newcomer wellbeing}

5.46 A significantly low level of newcomer wellbeing (Newcomer Wellbeing about 20\%) occurs when either: (1) no NGO is present in cities or (2) an NGO is present but the Custom Activities provided by the NGO are not branded towards newcomers. This latter condition means that even though the NGO is developing Custom Activities, newcomers are not interested in participating in them. As a result, the NGO SVQ actions Develop Custom Activities and Prioritize Activities Schedule have no effect on newcomer wellbeing. It is important to note that the NGO understanding of newcomer SVQs in Developing Custom Activities does not appear in these conditions. Thus, one recommendation of our model to decisions makers is: it is important for NGOs to Develop Custom Activities that newcomers will participate in, even if those activities are developed without an understanding of unsatisfied newcomer SVQs.

5.47 The most important variable related to avoiding low newcomer wellbeing (as well as low public opinion) is to have the NGO develop culturally sensitive activities and these do not need to address unsatisfied SVQs (i.e. avoiding low wellbeing outcomes does not depend on the satisfaction threshold). This insight could be useful for policymakers in better understanding the effects of certain value-based decisions on newcomer wellbeing and public opinion of how the refugee crisis is handled. In other words, organizing some type of activity is better than doing nothing at all, but it is better if the activities that are organized are aligned with the needs and interests of the newcomers.

5.48 The outcomes shown in Figure 7 report on the model execution after 1,000 time steps ( 1 time step $=1$ day). This reflects 3 years of time passing where a "steady state" of the model has been achieved with respect to public opinion and newcomer well-being. The model is parameterized as follows (other than the changes specified in the title of each graph to the NGO parameters): The COA improves facilities (Self-Enhancement) less frequently 


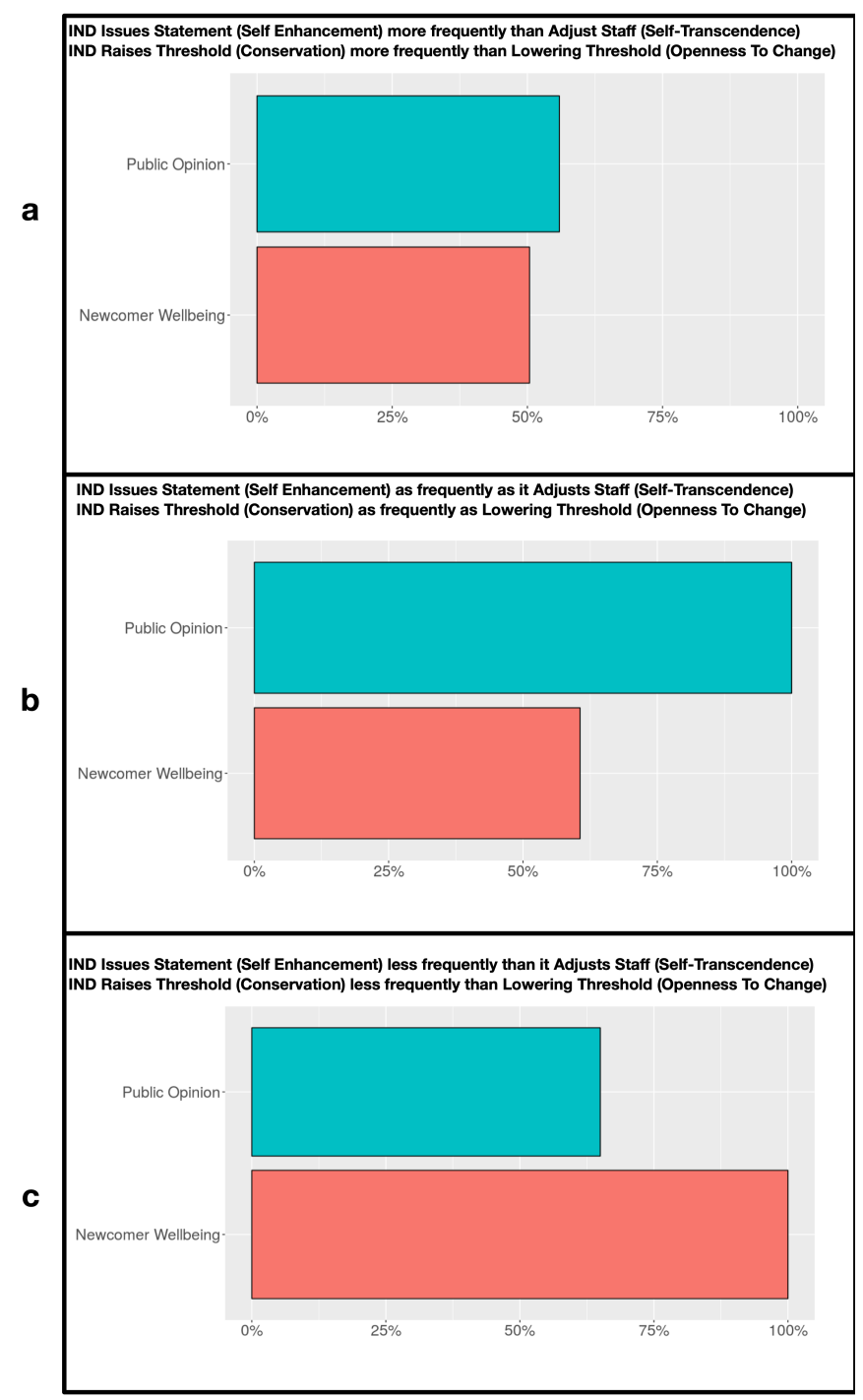

Figure 6: Comparison of how different Schwartz Values for the IND affect newcomer wellbeing and public opinion of newcomers.

than it invests in newcomers (i.e. provides a voucher to newcomers enabling them to travel to other cities to participate in activities) (Self-Transcendence) and the COA segregates newcomers (Conservation) less frequently than it adjusts staff to meet the needs of newcomers (Openness To Change). The NGOs conduct marketing campaigns (Self-Enhancement) less frequently than they develop Custom Activities (Self-Transcendence) for newcomers and the NGOs fundraise (Conservation) less frequently than they prioritize the scheduling of Custom Activities in the city to best meet the current needs of the newcomers (Openness To Change). The IND issues statements (Self-Enhancement) less frequently than adjusting staff (Self-Transcendence) and the IND raises the threshold newcomers are required to meet to remain in the country (Conservation) less frequently than it lowers the threshold newcomers are required to meet to remain in the country (Openness To Change).

\section{Conclusion}

6.1 In this article, we have described and analysed an agent-based model that characterizes the wellbeing of newcomers in the context of asylum logistics using Schwartz's theory of values as a decision procedure and wellbeing operationalization. This research is inspired by value sensitive design, which explicitly focusses on values in a design process. The Schwarz values have been used as theoretical input to build the model, whereas interviews and stakeholder meetings served to help connect values to concrete actions and vice versa. The 


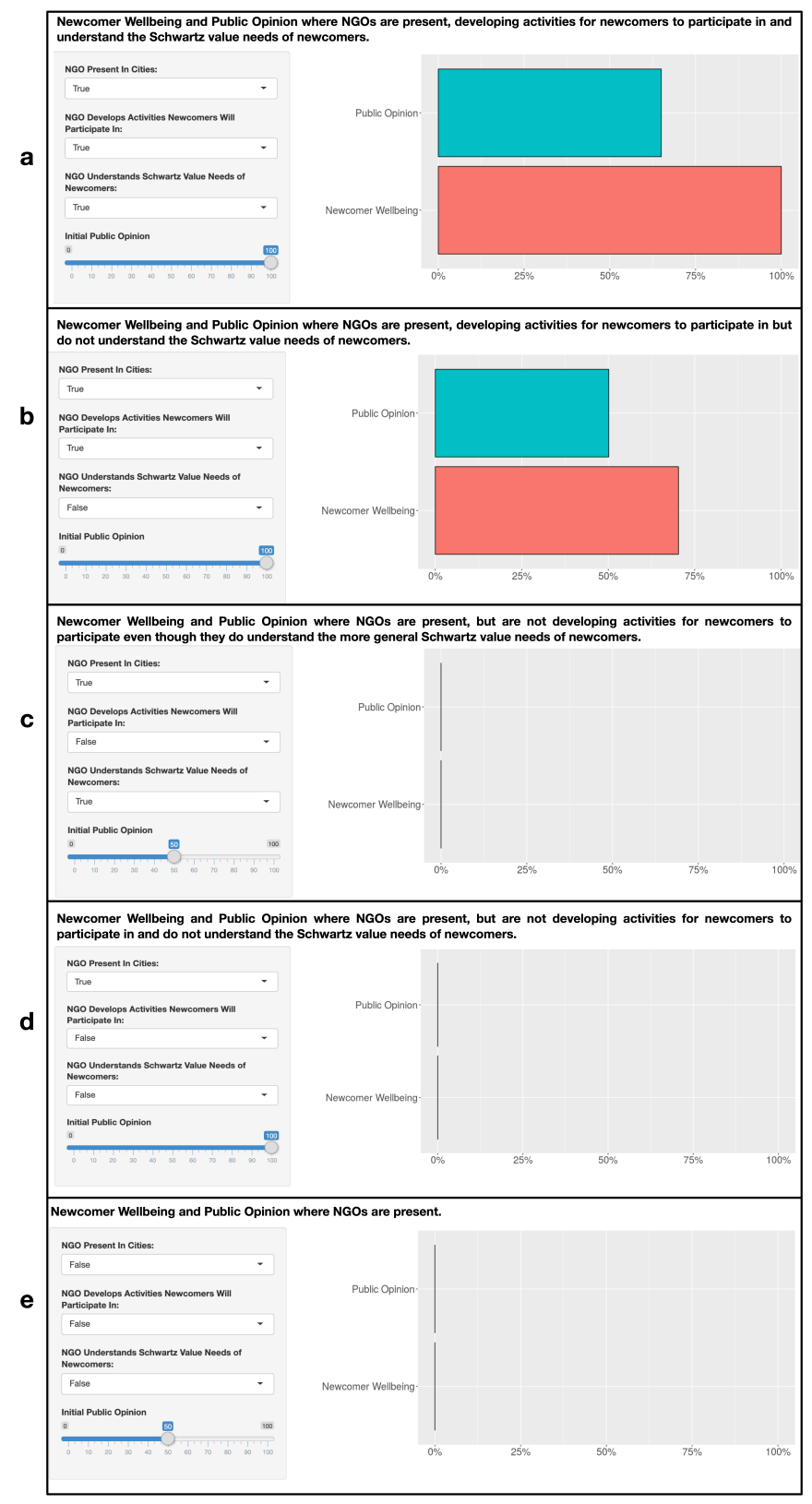

Figure 7: Comparison of how the simulation variables related to NGOs affect newcomer wellbeing.

theoretical input on which the model ran was informed by what was found in the interviews and stakeholder meetings.

6.2 The model shows how the constellation of stakeholders' actions, which directly impact on one other, also affects the stakeholders' wellbeing and public opinion about how the logistics around refugees is handled by the Dutch government. The model shows that the behaviour of key stakeholders may impact on the behaviour of other stakeholders, thus together creating a positive or negative effect on refugee wellbeing and on public opinion. The model shows how the value inspired decisions may have inverse effects, because of the complex interwovenness of stakeholders, refugee wellbeing and public opinion. The model serves as a 'discursive tool', allowing stakeholders to discuss with one another how the decision of one stakeholder impacts upon other stakeholders and how all these decisions affect the group they are meant to serve, namely refugees and Dutch society in general.

6.3 The conceptual novelty of our research is in the explicit modelling of values into an agent-based model of humanitarian logistics for refugees. We used an established theory of values in social literature, namely Schwartz's theory of basic human values. We constructed a website that can facilitate empirically informed discussions among stakeholders who do not necessarily interact on a practical level in reality, but whose actions and deci- 
sions impact on one another. When testing different scenarios through the agent-based model, the researchers concluded that the simulated situation, in general, corresponds to what happens in reality under the same conditions. We could therefore say that although the model is rather coarse (e.g., we used only four SVQ instead of all ten Schwartz's values), it does seem to have a good fit with reality. Different value-scenarios with different value trade-offs can be simulated, leading to different outcomes for refugee wellbeing and public opinion. The model could therefore be used to discuss value trade-offs with stakeholders.

6.4 We believe that our research is a good showcase of a combination of conceptual and empirical work on a societally relevant phenomenon: an agent-based model was designed in a value sensitive manner and discussed with stakeholders in order to address the urgent problem of humanitarian logistics for refugees.

\section{Discussion}

\section{Stakeholder feedback}

7.1 Stakeholder feedback on the model was given in a meeting where we presented and tested the model together with the stakeholders. One of the main points of concern was the definition of public opinion of the management of newcomer logistics. It was not clear to the stakeholders how to understand public opinion or how the percentages that were given by the model, depending on the chosen agent actions, were 'calculated'. Another point of discussion was the translation between acts or actions and values: could it not be that some actions have elements from more than one SVQ? In some cases, the stakeholders were not sure if the action that we described reflected the correct SVQ, for example in the case of 'language class': some argued that this is not a conservation SVQ action, but a self-enhancement SVQ action.

7.2 The stakeholders had suggestions for further refinement, for example by creating a visualization of some kind of "value measure" or "measure of wellbeing" for each agent. They wish to see how the choices of other agents affect their own values. They furthermore wish the model would give an explicit account of the value tradeoffs made by agents during their decision processes. However, providing this insight at a level that facilitates actionable decisions for stakeholders is difficult. Within an execution of an agent-based model millions of decisions are made by the agents. As a result, highlighting the trade-offs related to each decision will result in a deluge of information for stakeholders. Future work will attempt to identify an appropriate level of detail to quantify and communicate this information. Further elaborations of the model should be made by including other stakeholders, such as the mayors of cities, or the Dienst Terugkeer en Vertrek (DTenV, Repatriation and Departure Office) in the Netherlands.

\section{Conceptual issues}

7.3 Schwartz provides a functionalist account of human values: they are motivators to cope with the human condition. However, different accounts of what values are could be given and it would be interesting to see if and how the model would behave differently if we began with a different theoretical stance; for example, taking values as typical universal intuitions about what is desirable in this life and for the world in general, rather than 'assets' for survival. Another critique may be that Schwartz's approach is different from the value sensitive design approach, in the sense that in value sensitive design the value concerns are often about moral values. The interesting question is whether using a different set of values to build the model with would yield the same results? For example, if we use all ten of Schwartz's values, will the agent-based model give the same results? The main aim of our research was to see whether values could be meaningfully modelled, rather than to validate the model based on different value systems.

7.4 In our research, we explicitly focused on refugees as key stakeholders, but we could have chosen the Dutch population to be the focal stakeholders in the model. Changing this priority would probably yield different results.

7.5 As with any design, designing a model means that choices have to be made. We chose to limit the model in different ways; for example, refugees can only choose seven different activities and the other agents are even more limited in their actions, they can perform about three alternative actions. The agents were often strictly limited; for example, improving one's health can only be done by visiting a doctor or attending a sports activity (football). We are aware of these limitations. Nevertheless, this coarse model yields results that make sense. Refining the model by adding additional agents (such as the mayors of cities), or providing more possible actions or activities, would not necessarily lead to a better model. Adding more data or parameters can introduce 
noise by introducing factors that are not relevant for the phenomenon in the real world, but whose addition would nevertheless influence the results of the model. The art of social simulation is to find the minimal set of relevant parameters that can explain the emerging phenomena.

7.6 Our agent-based model leaves ample room for improvement and refinements, but it has been proven successful in bringing the attention of stakeholders in the management of logistics for refugees to the wellbeing of refugees, rather than a sole focus on efficiency and manageability of the situation. It is a tool to generate insights regarding value trade-offs. Technological developments often involve value trade-offs. In our research we made the value trade-offs explicit and created a way to show the effect of the different trade-offs in refugee logistics. It can be further refined and adapted to understand value trade-offs in (for example) climate change discussion and risk analysis.

\section{Model Documentation}

The supporting material includes the source code, which can be found here: https://github.com/phillipjw/ humanitarian_logistics/tree/reboot. The program is written in Python. The link to the interactive website can be found here: https://rgore-vmasc.shinyapps.io/integration-model//. The website represents a statistical meta model which summarizes the high-level results of our analysis.

\section{Acknowledgements}

We would like to thank the interviewees for their time and effort. This work is carried out at Eindhoven University of Technology and is part of the research program Responsible Innovation with project number MVI.16.011, which is partly financed by the Netherlands Organisation for Scientific Research (NWO). Additional funders are Prisma (The Netherlands), NWU Potchefstroom (South Africa), NOVA Institute (South Africa), Gunilla Bradley Institute (Sweden) and Association for Christian Philosophy (the Netherlands).

\section{Notes}

${ }^{1}$ For example, Dutch politician Wilders charged premier Rutte of discrimination against all Dutch citizens (https://rutte3discrimineert.nl).

2"I had so many conversations with newcomers and they were all done with the idea that they were sad and needed help, they just wanted to build a normal life. This is why we use the word newcomer" Julius Weise in Fallon (2018).

${ }^{3}$ Refugees include individuals recognized under the 1951 Convention relating to the Status of Refugees and its 1967 Protocol, persons recognized under the 1969 Organization of African Unity (OAU) Convention Governing the Specific Aspects of Refugee Problems in Africa, those recognized in accordance with the UNHCR Statute, individuals granted complementary forms of protection, and those enjoying temporary protection. The refugee category also includes persons in a refugee-like situation (https://www.unhcr.org/statistics/unhcrstats/ 5c52ea084/mid-year-trends-2018.html)

${ }^{4}$ Asylum-seekers (with 'pending cases') are individuals who have sought international protection and whose claims for refugee status have not yet been determined.

${ }^{5}$ The term 'refugee chain' refers to the overall asylum process in which a number of partners cooperate on the administrative, legal and logistical level of the asylum procedure. It is a common term in the Dutch asylum system, see herehttps://www.coa.nl/en/about-coa/chain-en-cooperating-partners/chain-partners The term 'refugee' formally denotes a legal status, however, in this article it is loosely referred to those people that are either externally displaced (they have not (yet) registered in the hosting country) or are in the process of requesting asylum. We also use the more neutral term 'newcomer' for them. In everyday language use is often - legally incorrect - spoken about refugees when they mean asylum seekers.

${ }^{6}$ See Report Vluchtelingen Logistiek en waarden, C.G. Boshuijzen- van Burken, April 23, 2018, unpublished.

${ }^{7}$ The Dublin III Regulation defines which State has the obligation to evaluate the asylum claims presented by people who arrive in Europe.

${ }^{8}$ We use the game of football in our model, because it is a sports activity that is offered in nearly all AZCs. But one can also read "Sports" in general whenever it states "Football". 


\section{References}

AIDA (2018). Netherlands: Processing times increase length of asylum procedures. Asylumineurope.org, Available at: http://www . asylumineurope.org/news/12-09-2018/ Retrieved September 12, 2018

AIDA (2019). Netherlands: Persisting delays on procedure put strain on reception. Asylumineurope.org, Available at: http://www.asylumineurope.org/news/05-11-2019/ netherlands-persisting-delays-procedure-put-strain-reception Retrieved November 5, 2019.

Altemeyer, B. \& Smith, M. (1988). Enemies of Freedom: Understanding Right-Wing Authoritarianism. San Francisco, CA: Jossey-Bass

Anderson, J., Chaturvedi, A. \& Cibulskis, M. (2007). Simulation tools for developing policies for complex systems: Modeling the health and safety of refugee communities. Health Care Management Science, 10(4), 331-339

Axtell, R. (2000). Why agents? On the varied motivations for agent computing in the social sciences. Working Paper Center on Social and Economic Dynamics, Brookings Institution and Johns Hopkins University

Bakker, L., Cheung, S. Y. \& Phillimore, J. (2016). The asylum-integration paradox: Comparing asylum support systems and refugee integration in the Netherlands and the UK. International Migration, 54(4), 118-132

Brandaõ Cavalcanti, L., Bergsten Mendes, A. \& Tsugunobu Yoshida Yoshizaki, H. (2017). Application of multiattribute value theory to improve cargo delivery planning in disaster aftermath. Mathematical Problems in Engineering, 2017(3), 1-12

Collins, A. J. \& Frydenlund, E. (2016). Agent-based modeling and strategic group formation: A refugee case study. Proceedings of the 2016 Winter Simulation Conference, 1289-1300. IEEEs Press

Crooks, A. T. \& Hailegiorgis, A. B. (2014). An agent-based modeling approach applied to the spread of cholera. Environmental Modelling \& Software, 62, 164-177

Curran, R., Smulders, F. \& van der Zwan, F. (2011). Evaluation of airport system of systems from a human stakeholder perspective using a Value Operations Methodology (VOM) assessment framework. 11th AIAA Aviation Technology, Integration, and Operations (ATIO) Conference, Including the AIAA Balloon Systems Conference and 19th AIAA Lighter-Than-Air Technology Conference

Dutch Council For Refugees (2016). About us. Available at: https://www .vluchtelingenwerk.nl/artikel/ dutch-council-refugees Retrieved September, 10, 2018

Epstein, J. M. \& Axtell, R. (1996). Growing Artificial Societies: Social Science from the Bottom Up. New York, NY: The MIT Press

Fallon, K. (2018). Newcomer or refugee? Why the Dutch are sensitive about labels. Available at : https://www.aljazeera.com/indepth/features/ newcomer-refugee-dutch-sensitive-labels-180716183946603.html. Retrieved February, 19,2020

Friedman, B. \& Hendry, D. G. (2019). Value Sensitive Design: Shaping Technology with Moral Imagination. Cambridge, MA: The MIT Press

Friedman, B., Kahn, P. \& Borning, A. (2006). Value sensitive design and information systems. In P. Zhang \& D. Galletta (Eds.), Human-Computer Interaction in Management Information Systems: Foundations, (pp. 348372). Armonk, NY: M.E. Sharpe

Gore, R., Diallo, S., Lynch, C. \& Padilla, J. (2017). Augmenting bottom-up metamodels with predicates. Journal of Artificial Societies and Social Simulation, 20(1), 4

Gore, R., Wozny, P., Digmum, F. P. L., Shults, F. L., Boshuijzen-van Burken, C. \& Royakkers, L. (2019). A value sensitive ABM of the refugee crisis in the Netherlands. Spring Simulation Conference (SpringSim), Tucson, AZ, USA, pp. 1-12

Gray, P. (2008). The nature of group decision support systems. In F. Burstein \& C. Holsapple (Eds.), Handbook on Decision Support Systems 1, (pp. 371-389). Berlin, Heidelberg: Springer 
Gregory, R. \& Keeney, R. L. (1994). Creating policy alternatives using stakeholder values. Management Science, 40(8), 1035-1048

Groen, D. (2016). Simulating refugee movements: Where would you go? Procedia Computer Science, 80, 22512255

Hailegiorgis, A. B. \& Crooks, A. T. (2012). Agent-based modeling for humanitarian issues: disease and refugee camps. The Computational Social Science Society of America Conference, Santa Fe, NM

Hattle, A., Yang, K. S. \& Zeng, S. (2016). Modeling the Syrian refugee crisis with agents and systems. UMAP Journal, 37(2), 195-213

Hebért, G. A., Perez, L. \& Harati, S. (2018). An agent-based model to identify migration pathways of refugees: The case of Syria. In L. Perez, E. K. Kim \& R. Sengupta (Eds.), Agent-Based Models and Complexity Science in the Age of Geospatial Big Data, (pp. 45-58). Berlin, Heidelberg: Springer

Izquierdo, S. S., Izquierdo, L. R. \& Gotts, N. M. (2008). Reinforcement learning dynamics in social dilemmas. Journal of Artificial Societies and Social Simulation, 11(2), 1

Keeney, R. L. (1996). Value-focused thinking: Identifying decision opportunities and creating alternatives. European Journal of Operational Research, 92(3), 537-549

Keeney, R. L. \& von Winterfeldt, D. (2007). Practical value models. In W. Edwards, R. Miles \& D. von Winterfeldt (Eds.), Advances in Decision Analysis: From Foundations to Applications, (pp. 232-252). New York, NY: Cambridge University Press

Kolfschoten, G., Grünbacher, P. \& Briggs, R. (2011). Modifiers for quality assurance in group facilitation. Group Decision and Negotiation, 20(5), 685-705

Mercuur, R., Dignum, V. \& Jonker, C. (2019). The value of values and norms in social simulation. Journal of Artificial Societies and Social Simulation, 22(1), 9

Oltermann, P. (2016). Merkel refuses to abandon refugee policy despite election setbacks. Available at : http://www.theguardian.com/world/2016/mar/14/ angela-merkel-refuses-to-abandon-refugee-policy-despite-election-setbacks Retrieved March, 14, 2016

Schwartz, S. H. (1992). Universals in the content and structure of values: Theoretical advances and empirical tests in 20 countries. Advances in Experimental Social Psychology, 25, 1-65

Schwartz, S. H. (2006). Basic human values: An overview. Available at : http://www.yourmorals.org/ Schwartz

Schwartz, S. H. (2012). An overview of the Schwartz theory of basic values. Online Readings in Psychology and Culture, 2(1)

Schwartz, S. H. \& Bilsky, W. (1990). Toward a theory of the universal content and structure of values: Extensions and cross-cultural replications. Journal of Personality and Social Psychology, 58(5), 879-891

Schwartz, S. H. \& Butenko, T. (2014). Values and behavior: Validating the refined value theory in Russia. European Journal of Social Psychology, 44(7), 799-813

Silverman, B. G. \& Bharathy, G. K. (2005). Modeling the personality \& cognition of leaders. University of Pennsylvania, ESE Departmental Papers

Suleimenova, D., Bell, D. \& Groen, D. (2017). A generalized simulation development approach for predicting refugee destinations. Scientific Reports, 7(13377)

Suleimenova, D. \& Groen, D. (2020). How policy decisions affect refugee journeys in South Sudan: A study using automated ensemble simulations. Journal of Artificial Societies and Social Simulation, 23(1), 2

Ulrich, W. (2003). Beyond methodology choice: Critical systems thinking as critically systemic discourse. Journal of the Operational Research Society, 54(4), 325-342

UNHCR (2019). Cijfers (Numbers). Available at: https ://www . unhcr .org/nl/wie-we-zijn/cijfers// Retrieved March 21, 2019 
van der Velden, M. \& Mörtberg, C. (2014). Participatory design and design for values. In J. van den Hoven, P. E. Vermaas \& I. van de Poel (Eds.), Handbook of Ethics, Values, and Technological Design: Sources, Theory, Values and Application Domains, (pp. 41-66). Dordrecht: Springer Netherlands

van der Weide, T. L. (2011). Arguing to motivate decisions. PhD Thesis, Utrecht University. Utrecht, the Netherlands

Vluchtelingenwerk (2019a). Gevangen in Een Vastgelopen Asielsysteem: Gevolgen En Verhalen Uit de Praktijk. Available athttps://www.vluchtelingenwerk.nl/sites/default/files/u32926/gevangen_in_ een_vastgelopen_asielsysteem.pdf Retrieved November, 2019

Vluchtelingenwerk (2019b). Vluchtelingen in Getallen 2019. Available at https://www. vluchtelingenwerk.nl/sites/default/files/Vluchtelingenwerk/Cijfers/20190722_vwn_ vluchtelingen-in-getallen.pdf Retrieved July 22, 2019

Voinov, A. \& Bousquet, F. (2010). Modelling with stakeholders. Environmental Modelling \& Software, 25(11), 12681281

Wozny, P. (2018). A value sensitive agent based simulation of the refugee crisis in the Netherlands. Master's Thesis, Utrecht University. Utrecht, the Netherlands

Zia, A., Hirsch, P., Songorwa, A., Mutekanga, D. R., O’Connor, S., McShane, T. \& Norton, B. (2011). Cross-scale value trade-offs in managing social-ecological systems: The politics of scale in Ruaha National Park, Tanzania. Ecology and Society, 16(4), 7 